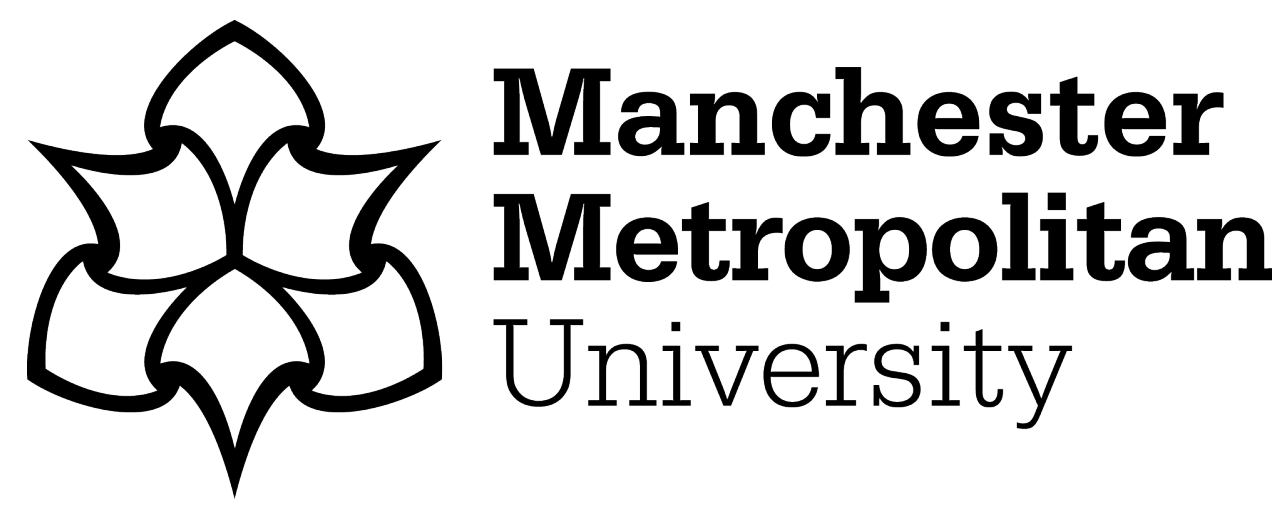

Ralphs, R and Gray, PM (2018) New psychoactive substances: new service provider challenges. Drugs: Education, Prevention, and Policy, 25 (4). pp. 301-312. ISSN 0968-7637

Downloaded from: https://e-space.mmu.ac.uk/619693/

Version: Accepted Version

Publisher: Taylor \& Francis

DOI: https://doi.org/10.1080/09687637.2017.1417352

Please cite the published version 


\title{
New Psychoactive Substances: New service provider challenges
}

\author{
Rob Ralphs and Paul Gray \\ Manchester Metropolitan University, UK
}

\begin{abstract}
This paper presents findings from a six-month study of New Psychoactive Substance (NPS) use in Manchester, UK. Drawing on interviews with 53 NPS users and 31 stakeholders, the paper documents a notable shift in the drug using landscape. It highlights how the homeless community - traditionally associated with alcohol dependency and problematic intravenous heroin and/or crack cocaine use - are now switching to smoking synthetic cannabinoid receptor agonists, while men who have sex with men (MSM) and engage in chemsex - who have traditionally been strongly associated with the recreational use of ecstasy and other stimulants - are now developing problematic intravenous drug using habits. The paper goes on to discuss the implications of this shift for existing models of treatment service delivery. In particular, it outlines the necessity for treatment services to develop innovative engagement strategies, alongside clearer referral pathways and improved service integration.
\end{abstract}

\section{Key Words}

new psychoactive substances, synthetic cannabinoid receptor agonists, chemsex, substance use treatment services

\section{Introduction}

'There needs to be something that's specific for NPS'. (SH22, Supported Housing Manager)

Over the past decade the UK drugs landscape has undergone a period of significant change. At the forefront of this change has been the introduction of a wide range of new or novel psychoactive substances (NPS)i, with over 500 NPS identified by the European Early Warning System to date (EMCDDA 2016). While the recent focus on NPS has centred around the legislative response to the growing number of NPS, in particular the Psychoactive Substances Act 2016, and the effectiveness of this response (Stevens et al. 2015), there has been less development regarding the treatment response to NPS. The harms associated with this rapid influx of NPS over the last ten years has led to debates about whether specific services are required to respond to NPS. This paper engages with this discourse through the presentation of findings from a six-month study of NPS prevalence in Manchester, England.

Of the plethora of new or novel substances that have been identified, only a smaller number have cemented themselves amongst the traditional menu of illicit drugs in the UK. These include nitrous oxide, mephedrone, ketamine, GBL (gamma butyrolactone), GHB (gamma hydroxybutyrate) and synthetic cannabinoid receptor agonists (SCRAs), often referred to as 'Spice' in the UK. The consumption of these drugs is often associated with particular subpopulations such as students, clubbers, LGBT, prison and homeless communities. In this paper, we focus attention on two distinct subpopulations and the emerging NPS drug trends within them - namely the homeless community and SCRA use, and men who have sex with men (MSM) and engage in 'chemsex', defined as sexual activity engaged in while under the influence of drugs such as methamphetamine, mephedrone and/or GHB/GBL (NEPTUNE 2015), with intravenous use being common. ii 


\section{Background}

The increasing number of NPS have caused concern amongst substance misuse service providers and health care professionals, and the extent to which existing services meet the needs of NPS users has generated much discussion. Since the development of drug services as a response to the emergence of heroin outbreaks in the 1980s (Parker et al. 1987; Parker et al. 1988; Pearson 1987) and the increase in recreational drug use amongst young people, accelerated by the onset of the rave and dance music culture (Parker et al. 1995; Thornton 1995), treatment services in the UK have established themselves around the needs of so-called problematic users of heroin and crack cocaine and recreational users associated with the ACCE profile of alcohol, cannabis, cocaine and ecstasy (Williams \& Parker 2001). It has been suggested that new services and interventions are needed in response to the emergence of NPS trends. For example, the All-Party Parliamentary Group for Drug Policy Reform (2013) highlighted that users of NPS are often higher-risk groups who have multiple and complex needs. They conclude that generic services without specialist training will struggle to deliver successful treatment and intervention to these individuals. Likewise, the Local Government Association (2015) argues that drug services should recognise and understand who uses NPS to ensure they have the right skills and knowledge to tailor their services accordingly. In stark contrast, Chatwin et al. (2017) emphasise how many users of NPS consume these substances alongside traditional drugs, suggesting that their substance use should be treated holistically, challenging the notion that NPS users warrant a specialised response or service. In a similar tone, Sumnall et al. (2017) have argued that responding to NPS requires treatment workers to build upon the skills and competencies that they are likely to already possess, developing interventions used for traditional drugs, and that an entire new service response is not necessary. Likewise, in a review of the pharmacology and toxicology of four NPS, Tracy et al. (2017) asserted that although knowing the precise drug/s used by an individual helps to provide better informed patient care the response in terms of the management of toxicity is broadly similar regardless of whether an individual has taken NPS or an established recreational drug. In light of these competing discourses this paper draws upon empirical evidence to inform the debate about whether specific service development is necessary to respond to novel forms of drug use and if so what this development should look like.

\section{Existing NPS service engagement}

The percentage of those accessing treatment services for an NPS-related problem in England is currently low (Public Health England 2014b). These low levels of engagement are mirrored in Europe where NPS users in treatment represent less than one percent of all treatment demands (Pirona et al. 2017). As a consequence of the small proportion of NPS users engaging with treatment services, some have warned that it is key that services do not become '... too fixated on NPS but instead focus on safer decisionmaking around substances as a whole’ (Blackman \& Bradley 2017:75). However, Bowden-Jones et al. (2014) argue that lack of engagement with treatment services is a consequence of NPS users' perceptions of drug services. Historically drug treatment services have specialised in addressing the needs of opioidusing clients - this user group still represent the largest and most problematic drug using population entering specialist treatment (40 per cent) - resulting in NPS users viewing drug treatment services as 'not for them' and unable to meet their needs (Local Government Association 2015). As Pirona et al. (2017) have recently noted, this perceived gap in service provision risks leaving vulnerable populations neglected and their needs unaddressed. Consequently, Bowden-Jones et al. (2014:4) call for treatment services to 'widen the front door', making the needs of NPS users their 'core business' and placing NPS on an equal footing with opiate and alcohol service user needs.

While debate continues regarding how services should respond, what is certain is that the UK drug landscape is undergoing significant change; it is therefore important that existing services keep pace with this changing user profile, as well as meeting the demands of more established patterns of substance use. 
Given the complex and diverse nature of this issue, it is evident that further research is needed to confirm whether existing approaches to drug treatment are effective for tackling the new challenges presented by NPS (Bowden-Jones et al. 2014). This paper aims to inform this debate by drawing upon the experiences and views of two distinct sub-populations of NPS users in Manchester - the homeless and MSM engaged in chemsex - and the practitioners and stakeholders who work with them. The paper starts by highlighting the emerging shift evident in the drug use amongst these two sub-populations. It then moves on to discuss the implications of this shift in terms of both changes in user needs, and the issue of non-engagement with treatment services. The paper finishes by discussing the distinct strategies that are required to successfully engage with these two sub-populations of NPS users.

\section{Methodology}

Our qualitative research was undertaken in Manchester, UK between January and June 2016. The research location is significant as Manchester has been at the forefront of media attention in recent years for the use of 'Spice' amongst the homeless community (BBC1 2016; Perraudin 2017; The Vice 2014; Williams 2017a, 2017b; Williams \& Macpherson 2017). Furthermore, recent research has suggested that Manchester (along with Brighton) has the fastest growing chemsex scene in the UK (SIGMA 2016). Findings from a recent sex survey of nearly 900 MSM respondents in Greater Manchester found that six per cent reported using at least one of the three main substances associated with chemsex (crystal methamphetamine, GHB/GBL or mephedrone) in the previous four weeks (Hickson et al. 2016).

Fifty-three NPS users - 38 SCRA users (33 male, 5 female) and 15 chemsex users - were purposively sampled. Semi-structured face-to-face interviews were conducted with all users. Local service providers reported low levels of engagement amongst both of these user communities. Consequently, a decision was made to purposely target those users not currently engaged with service providers. A range of service providers working with the homeless community facilitated the interviews with homeless SCRA users. These providers included: homeless outreach teams; supported accommodation providers; probation approved premises; homeless drop-in centres; and a medical practice that catered for the homeless. The term 'homeless' in this study encompasses rough sleepers, and those using city centre homeless services who were living in a range of temporary or emergency accommodation such as bed and breakfasts, hostels, supported housing and approved premises for those recently released from prison. LGBT community organisations facilitated access to MSM involved in chemsex. Further interviewees were then obtained through the use of a snowball sample. Chemsex users were defined as using at least one of the three drugs associated with this scene (GHB/GBL, mephedrone or crystal methamphetamine) who also self-defined as engaging in chemsex and included male sex workers who offered chemsex services.

A further 31 semi-structured face-to-face interviews were conducted with staff and practitioners from a range of services in the area, including: adult and young people's drug and alcohol services; offender management services (including prison and probation); the police; supported housing providers; approved

premises; homeless day centres; homeless outreach teams; young people's homeless services; young people's mental health services; homeless GP surgeries; sexual health services; LGBT organisations; and Accident and Emergency services. The interviews with users and service providers ranged in length from 20 to 150 minutes. All 84 interviews were digitally recorded and fully transcribed and analysed using NVivo qualitative data analysis software.

\section{An emerging shift in the drug using landscape}

The fieldwork uncovered evidence of an unparalleled change occurring in the profile of so-called 'problematic drug users', in particular the traditional profile of intravenous drug users. This in turn 
challenges the traditional dichotomy of recreational and problematic drug use (Askew 2016; Macdonald $\&$ Marsh 2002; Pilkington 2006). We found user groups often deemed at risk of initiation into heroin use - either whilst serving custodial sentences, or as a result of living on the streets or hostels - are currently being introduced to SCRAs instead (HMIP 2015, 2016; Ralphs et al. 2017; User Voice 2016). With many reporting dependency and problematic use of SCRAs. Notably, users and homeless sector workers regularly reported that heroin and crack cocaine users were switching from heroin to SCRAs.

'It [Spice] has replaced a lot of other drugs. ... A lot of my friends have given up heroin and crack addictions, and they now smoke the Spice. I'm the same. I've given up an alcohol, crack and heroin habit and I just smoke Spice. I gave up cannabis as well'. (SC8 Male, mid 20s, Supported Housing)

Compared to their 1980s, 1990s and 2000s counterparts (Fountain \& Howes 2001; Johnson et al. 1997) problematic substance use among rough sleepers and those in hostels and other supported housing is now much less likely to involve intravenous injection and much more likely to involve the use of SCRAs.

'I've probably got about 40 clients on my caseload at the minute who are street homeless. Of them I'd say about 95 per cent of them take Spice'. (SH2 Support Worker for Young Street Homeless)

'Every single person I know smokes it'. (SC22 Male, late 20s, Street Homeless)

In line with Ralphs et al.'s (2017) and User Voice's (2016) studies of SCRA use within English prisons, the onset of use for those sleeping on the streets was tied to a need to 'kill time' and make life on the streets more bearable. Interviewees talked of using SCRAs as a form of 'mindscaping' to help them escape their lived realities (Cohen \& Taylor 1976) as well as a form of self-medication (Fountain \& Howe 2001; Klee \& Reid 1998).

'If you're on the streets and you're cold, you have a spliff off Spice, it warms you up, trust me I'm not joking'. (SC9 Male, early 20s, Street Homeless)

'It helps you sleep. [The] amount of times I've done that in the car park, I used to sleep in the car park [and] Spice knocks you to sleep’. (SC5 Male, early 20s, Street Homeless)

In this respect, the use of SCRA to block out the day-to-day realities and traumas of their lives appeared to correspond with the functionality of opioid use (see Gray et al. forthcoming). The use of substances to self-medicate amongst homeless populations is well-established. Klee and Reid (1998) note how the particular nature of the stressors endemic in the homeless lifestyle leads to increased vulnerability to such self-medication. A more recent Homeless Link audit found that poor mental health was a significant contributing factor to substance use with 80 per cent of those surveyed reporting at least one mental health issue, and almost all of these reporting the use of drugs and/or alcohol as a coping strategy (Homeless Link 2014). The consumption of SCRAs was frequently reported to enable users to block out the realities of life on the streets.

'They'll just have a really strong [SCRA] joint... to help them sleep and just block it out really, block out life 's traumas'. (SH30 Homeless Day Centre Manager)

Alongside this shift away from injecting drugs within the homeless community, the research also found evidence of a change in the ingestion route of drugs within the emergent chemsex scene amongst MSM. A substantial number of those involved in this scene have moved beyond the recreational use of traditional 
substances such as ecstasy and cocaine (Bourne et al 2015; Keogh 2009) to the injecting or 'slamming',iii of crystal methamphetamine and mephedrone. This finding is consistent with a recent national survey of 15,000 MSM which revealed that seven per cent of survey respondents in England claimed to have used at least one of the three chemsex drugs in the last month, and just under two per cent reported injecting drugs in the past year (SIGMA 2016).

\section{'About 29 per cent of our [chemsex] population are injecting'. (SH11 Chemsex Practitioner)}

A recurring theme in the interviews with MSM and healthcare professionals was the sharp escalation of the chemsex scene in Manchester. For example, all those MSM we interviewed made similar observations about the noticeable rise in the Manchester chemsex scene.

'Over the last couple of years, the random sort of requests for chemsex and chemsex parties that I get [through Apps] have skyrocketed... It seems really, really huge now up North. Maybe that just has to do with ... Manchester becoming this sort of internationally recognized sort of queer Shangri-La that it is, more people sort of moving here and visiting here on weekends and stuff'. (MSM2 Sex Worker, mid-30s)

Practitioners working with this client group also highlighted the wide range of MSM accessing chemsex services.

'The people we see at the REACH iv clinic... [are] like complete opposite ends of the spectrum. So you'll get a youngish really vulnerable lad who's maybe doing sex work and a number of drugs. And then you'd get a doctor... There's not a typical stereotype'. (SH28 Chemsex Substance Use Practitioner)

The motivations to use and in particular to 'slam' mephedrone and crystal methamphetamine was often linked to heightened sexual pleasure.

'Once you've had sex on crystal [methamphetamine] there's no going back. Normal sex just doesn't cut it'. (MSM13, mid-40s)

The implications of the shift outlined above are twofold. Firstly, the treatment service needs of both homeless users of SCRAs and MSM involved in chemsex have changed from the needs that would have traditionally been associated with these two user groups. Secondly, evidence from users suggests that, as a direct result of these changes, existing treatment services are unable to fully meet the needs of SCRA users and MSM involved in chemsex. This has resulted in a lack of treatment service engagement amongst these two groups of NPS users. The paper now moves on to discuss each of these points in turn.

\section{The implications of this shift: Changes in user needs}

Emerging evidence has suggested that SCRAs have the potential to lead to acute drug dependency (Ralphs et al. 2017). In line with the findings of Every-Palmer (2011) and Zimmerman et al. (2009), SCRAs were perceived by users and stakeholders to have more negative psychological and physical withdrawal symptoms than a range of other substances. For example, throughout the research, many drug dependent users of SCRAs with considerable lifetime experience of heroin, crack cocaine, and a variety of other illicit and prescription drugs consistently referred to SCRAs as resulting in more acute withdrawals than other substances they had previously used. Indeed, former dependent heroin and crack cocaine users unanimously referred to 'Spice' as the most addictive substance that they had ever taken, with the most acute withdrawals and 'rattle' they had experienced. Daily consumption was common with many users 
reporting using to prevent unpleasant side effects that they attributed to withdrawal symptoms. These typically included: problems with sleep; excessive sweats; loss of appetite; hallucinations and paranoia; severe stomach cramps; diarrhoea; and vomiting.

'I was addicted, very addicted, I was bad. It was hard to get out of, really hard. It's the hardest thing I've ever had to do. ... Spice is definitely the most addictive [substance]'. (SC19, Male, late-20s ex-Heroin and Crack User, Approved Premises)

'You get no sleep. Hot and cold sweats, spewing up, you've got diarrhoea'. (SC27, Male, early-30s, Homeless)

'It's horrible. Hallucinations, stomach cramps, shits, being sick, can 't eat nothing, paranoia, everything'. (SC17, Male, mid-30s, Approved Premises)

International research regarding the negative impact of SCRA use on users' mental health has emerged in recent years (Barratt et al. 2013; Bebarta et al. 2012; Castellanos et al. 2011; Every-Palmer 2011; Harris \& Brown 2013; Hurst et al. 2011; Thomas et al. 2012; Van der Veer \& Friday 2011; Zimmerman et al. 2009). A Home Office review of NPS identified a range of negative psychopharmacological effects associated with SCRAs including anxiety, severe depression, self-harm, paranoia and psychosis (Home Office 2014). Our findings support this, with users attributing a variety of mental health effects to their use of SCRAs.

'Heavy bouts of psychosis and depression, crippling depression... It's mad, proper crazy, like a whole different dimension'. (SC24, Male, mid 20s, Supported Housing)

'You may as well just get a syringe of paranoia and whack it in your vein. That's what I felt like after a couple of drags of Spice’. (SC2, Male, late 30s, Street Homeless)

Those users we interviewed that disclosed existing mental health problems prior to using SCRAs, consistently acknowledged that their use of synthetic cannabinoids intensified these issues.

'I've got mental health problems anyway, previous to the Spice, but the Spice has amplified them'. (SC29, 24-year old Male, Street Homeless)

'I've got paranoia and anxiety [anyway] but it [Spice] makes it a lot worse'. (SC34, Male, early 20s, Supported Housing Focus Group)

Recent reports from the Inspectorate of Prisons for England and Wales (HMIP 2014, 2015) and the Ministry of Justice (2016) have all linked the rise in self-harm and suicides in custodial settings with an increase in the consumption of SCRAs. Our findings provide further support for this association. Users often described episodes of self-harming or suicidal thoughts after consuming SCRAs.

'I've had a few episodes where I've hurt myself, self-harmed and that'. (SC38, Male, mid 20s, Street Homeless)

'I could feel my head going. I was getting quite concerned. I was self-harming'. (SC18, Male, late 20s, Approved Premises) 
'If you don't have a spliff of it [Spice], it can make you think in your head that you want to commit suicide. ... I've gone to jump off bridges and everything'. (SC6, Female, early 20s, Young people's homeless dropin)

It is important to note that many of the homeless people we interviewed are living in conditions that are likely to lead to poor mental health or to exacerbate existing mental health conditions. The same can be said for those using SCRAs in custodial settings. Nevertheless, as we noted earlier, some international studies have started to evidence the capability of SCRAs to initiate mental health issues in otherwise healthy young adults (Castellanos et al. 2011).

'I think mental health problems and NPS usage go hand in hand, definitely. If you haven't got mental health problems then you probably will do after smoking Spice'. (SC26, Homeless Charity Coordinator)

Turning attention to those involved in chemsex scenes, the need to address users' mental health remains but is accompanied by the clear necessity for sexual health needs to be addressed alongside users substance use. Indeed, there is increasing evidence that there are three distinct, but overlapping, areas in which MSM populations bear a disproportionate burden of ill health: sexual health - notably HIV infection, as well as, infectious syphilis and gonorrhea (Health Scrutiny Committee Meeting 2016); mental health; and the use of alcohol, drugs and tobacco (Public Health England 2014a). In particular, there is growing concern over the involvement of a minority of MSM engaged in chemsex (Bourne et al. 2014). Chemsex commonly involves sex that can sometimes last several days. It leads to a heightened sexual focus and enables more extreme sex, for longer, often with more partners and with less concern about contracting STIs and blood borne viruses (BBVs), such as, HIV, or taking protective measures against these infections. The injecting or 'slamming' of crystal methamphetamine and mephedrone increases the risk of injectionrelated infections and blood-borne viruses like HEP C, HIV and HCV (Dolengevich-Segal et al. 2016).

'The ones who are not injecting are exposed to just as much risks in regard to chemsex. It's the HIV negative guy who's doing $G$ and sniffing mephedrone, who's having sex with 15 partners who's going to catch HIV and transmit it to 30 more in the next month. That's the highest risk'. (SH11, Chemsex Practitioner)

Overdoses and black-outs linked to the use of GBL/GHB are common and its use has raised concerns about users' ability to consent to sex. Therefore, the health risks associated with chemsex are more severe than those associated with other scenes commonly linked to recreational substance use. The combination of factors associated with chemsex has been described as 'a perfect storm for transmission of both HIV and $\mathrm{HCV}$, as well as a catalogue of ensuing mental health problems' (Kirby \& Thornber-Dunwell 2013:101). These include: chronic depression; anxiety; paranoia; drug-induced psychosis; depression; and suicidal thoughts (Almeida et al. 2009; King et al. 2008; McFall 2012).

'The most extreme client that I had was a client that presented at generic drugs services... He was just chemsex all week, day and night... [And] his mental health... [he was] suicidal every week... Then he got sectioned a few times... He had HIV, and now he's in [HMP Manchester] Strangeways'. (SH8, Chemsex Substance Use Practitioner)

Narratives of shame and stigma also emerged in stakeholder interviews as underlying reasons why MSM engaged in chemsex. 
'For many, I think there is a deep rooted reason around stigma, shame, identity, even internalised homophobia, that their use of drugs and involvement in chemsex is masking'. (SH7, LGBT Counsellor)

The heightened risk of the transmission of STIs and BBV as a result of engaging in the chemsex scene requires a joined-up sexual health and substance use response (Department of Health 2013; Public Health England 2015). In addition, practitioners working with this group highlighted the potential impact on users employment, finances, housing, partnerships and friendships in stating that MSM involved in chemsex require services that go beyond drug treatment to encompass mental health services, counselling, sexual health and HIV services. A consideration of other prescribed medications, such as antiretrovirals, is essential due to potentially harmful drug interactions and contraindications and the possibility of increased toxicity. For example, recreational drug use has consistently been linked to lower rates of HIV medication adherence (Antoniou \& Tseng 2002; Halkitis et al. 2005; Haubrich et al. 1999; Romanelli et al. 2003). The use of drugs by HIV-positive individuals who have been prescribed antiretroviral medications is therefore a source of concern. Indeed, adverse interactions between agents commonly prescribed for HIV infection and recreational drugs may also have serious clinical consequences (Connor, 2004; Harrington et al. 1999; Henry \& Hill 1998; Pacifici et al. 2001a; Pacifici et al. 2001b).

' $G H B / G B L$ can also cause severe nausea, vomiting and gastro-intestinal irritation, which will all adversely affect absorption of the antiretroviral agent'. (SH10, Chemsex Clinic Practitioner)

'I think people forget that some of the other drugs, the recreational drugs, have an effect and can compromise the antiretroviral treatments. But also, they can enhance them and exacerbate them, turn them into more of a poison, either the antiretrovirals or the drug itself, the recreational drug... So it can weaken the HIV drugs, which is not good, or it can double or treble the strength of it, which is not good either'. (SH25, Sexual Health Nurse)

The perceived lack of support and expertise around users' sexual and mental health was a barrier to engagement. The following section further highlights the issue of non-engagement with traditional treatment services for these two NPS user groups.

\section{The implications of this shift: Service user non-engagement}

'There are people who we're seeing on the streets a lot, young people particularly, ... they're not engaging with any services at all'. (SH17, Homeless Case Manager at City Centre Medical Practice)

Despite the complex and often interrelated needs identified above, throughout the fieldwork process, it became apparent that users of SCRAs and chemsex substances had a lack of knowledge of existing service provision and, perhaps most concerning, outdated views and perceptions of who treatment services are targeted at and what services could offer. For example, we came across many young SCRA users in particular who viewed treatment services as a place for heroin and crack users or a place to obtain clean needles.

'Why would I want to go to a place with druggies?' (SC32, Male, early 20s, Street Homeless)

'Do you know what they're for, them drugs services? To give new needles and I don't use needles, so why do I need to go there?' (SC36, Male, early 20s, Supported Housing) 
Professionals working with this user group further supported these views. They discussed how the stigma that is associated with treatment services often acts a barrier to engagement amongst NPS users.

'The services that are already set up, they [NPS users] think they're for the heroin users. They don't feel like it is for NPS'. (SH15, Supported Housing Staff)

'They're addicted to NPS, so why would they go to somewhere that deals with class A drugs... They don't want to be defined as that kind of drug user'. (SH12, Supported Housing Manager)

Added to this, many SCRA users lacked the knowledge of what support was available or held the perception that treatment services lacked the knowledge base to work with NPS users which deterred them from engaging with services.

'I don't know who's available and what's available'. (SC15, Male, early 30s, Street Homeless Medical Drop-in)

'They've got nothing to help you because they don't know what's in it... They don't know anything, they're fucking shit'. (SC18, Male, early 20s, Supported Housing)

'[INT: If you wanted to get off it in the future, would you go to a drug service for help?] No, because I know they don't really know much about it so I'd probably think "Well you're just wasting my time as much as I'm wasting yours"'. (SC20, Male, mid 20s, Medical Centre Homeless drop-in)

The perception that treatment services do not know how to deal with NPS users was further supported by frontline workers and was often raised during interviews with practitioners.

'[Treatment service name] don't know [how to deal with Spice] and they're the biggest drug service'. (SH4, Support Worker for Young Street Homeless Project)

'I'm not entirely sure how much faith I have in any of those services in these issues. ... I don't think there are currently any agencies that would offer practical help'. (SH29, Homeless Outreach Worker)

One of the most frequently cited factors by SCRA users regarding non-engagement was the perception that treatment services could not prescribe substitute medication. This was particularly cited as an issue by users who had previously engaged with services for heroin dependency. These experienced substance users often compared treatment services for heroin users with what they perceived to be available for users of SCRAs.

'What's on offer that's going to make people come in? What's out there to substitute Spice, treatment wise?... Going into treatment as a heroin user, I know I'm not going to rattle every day [but] for Spice, there's not any of these things, so why am I going to get treatment?' (SC16, Male late 30s, ex-heroin user)

'A chemical of some sort [to substitute SCRA use] is going to get me to treatment because that's what I know'. (SC21, Male, late 30s, Ex-service user for heroin and crack)

Professionals working with this user group also cited the lack of substitute medication to replace SCRA dependency as a barrier to treatment engagement. 
'For other drugs there's a clear route. If someone's using heroin or crack, it's very easy for me because there's a nice route which I can go down, generally by prescribing alternatives. But [with SCRAs] there's no clear route'. (SH24, Homeless Outreach Worker)

The stigma and stereotypes attached to traditional services that we outline above were also apparent in relation to the non-engagement of MSM involved in chemsex with traditional substance use treatment services. In particular, views relating to the lack of knowledge and competency evident in the homeless population's perceptions of treatment staff were also present among chemsex users when they discussed their drug treatment options.

'We need to work differently... because a lot of people [engaged in chemsex] probably wouldn't access a needle exchange because they associate it with opiate drug users. There's so much stigma attached to using a needle exchange’. (SH8, Chemsex Substance Use Practitioner)

While shame and stigma were often cited as reasons for non-engagement with traditional treatment services, it was noted that for those who want to engage with services due consideration needs to be afforded to opening times in order to increase chemsex user engagement. Stakeholders and users highlighted that in comparison to traditional intravenous drug using populations many MSM involved in chemsex are in full time employment and therefore require more flexible and extended opening times.

'The main thing is to make appointments available... outside of traditional nine to five working hours... I can 't fucking get out of work on a Wednesday at four, and a lot of other people can 't'. (MSM8, early 40s)

Establishing evening opening times and/or weekend clinics that enable appointments to be made outside the typical Monday to Friday 9-to-5 working day was frequently cited as preferable. In addition to opening times the location was viewed as important. The lack of easily accessible service provision in the city centre was frequently cited as a barrier to engagement with this cohort.

'A city like Manchester should have HIV testing and just general sexual health places on every fucking corner you know. . . I mean the city centre is an obvious choice. In and around Canal Street [the heart of the 'gay village'], again, really obvious choice'. (MSM11, Mid 30s)

In discussing the developing culture of intravenous drug use associated with chemsex, there were suggestions for a needle exchange at the heart of the LGBT community.

'I think the [gay] village needs a needle exchange, ... at the weekends in particular. Because that's the other thing isn't it. ... Needle exchange provision at the weekend is limited'. (SH23, Senior Substance Use Practitioner)

\section{Increasing user engagement with treatment services}

The findings outlined so far have highlighted that, despite having complex needs, the two user groups discussed in this paper displayed a lack of engagement with existing treatment services. The Public Health England JSNA guidance on needs assessment (Section 1.2, Public Health England 2014b) highlights the importance of establishing the levels of drug treatment penetration by dependent users. Our research found that there is a sub-population who describe their consumption of SCRAs and chemsex drugs as 'dependent' or 'addictive', yet they are not engaging with services. For some users this non-engagement stemmed from a lack of awareness and negative perceptions of the services on offer. While for others, the limitations of existing service delivery proved to be the primary barrier to engagement. There is an ongoing debate 
regarding how much services need to adapt when working with NPS users (All-Party Parliamentary Group for Drug Policy Reform 2013; Blackman \& Bradley 2017; Local Government Association 2015; Sumnall et al. 2017). It is argued by many (McCleod 2012; Tracy et al. 2017) that the same harm reduction advice, motivational interviewing techniques and psychosocial interventions, identification of triggers and so forth can be applied regardless of the substance involved. This paper begins to shift the debate away from a focus on the need for services to adapt the interventions they currently offer, towards a focus on the distinct strategies that are required to successfully engage with the sub-populations of NPS users discussed in this paper. We propose a threefold approach that focusses on improved integration of existing services, the need for clearer referral pathways, and the need for treatment services to develop more innovative engagement strategies.

\section{Improved integration of services}

For years, scholars have highlighted the need for effective dual diagnosis programs that combine mental health and substance abuse interventions and are tailored to the complex needs of clients with comorbid disorders (Drake et al. 1993; Drake et al. 2002; Minkoff 1991, 2001). Nevertheless, a key theme arising from the research was the challenge of managing clients with complex needs, in particular dual diagnosis, and providing appropriate and effective support around their use of NPS. As the quotes below illustrate, an issue that consistently featured in our interviews with both NPS users and a broad range of professionals was in relation to the insufficient current level of mental health support available to users of NPS.

'The problem with mental health and substance misuse is, because of the way services are, the first thing they've got to do is reduce substance misuse before they'll do mental health work'. (SH1, Support Worker, Young Homeless)

'We can't get a dual diagnosis because they [the mental health services] are saying it's drug-induced psychosis, and they [the substance use services] have to deal with the drug problem before they [the mental health services] deal with the mental health problem'. (SH14, Young People's Substance Use Practitioner)

A broad spectrum of professionals were keen to stress that it is imperative service users with co-existing mental health and substance use problems are viewed and treated holistically. One way to achieve this would be to have substance use and mental health teams working in a much more integrated fashion.

'I would like to see mental health services work in partnership with substance misuse services, to kind of have a single point of entry’. (SH21, City Centre GP)

'Substance use and mental health have become completely separate services and unfortunately [they] don't talk to each other... We see this often... they haven't got any kind of links or anything and it's unfortunate because we should be working hand in hand'. (SH27, A\&E Consultant)

However, the difficulties around accessing mental health provision for NPS users is exacerbated by the apparent reluctance of mental health services to engage with those NPS users who are exhibiting mental health problems as a result of their substance use.

'Mental health look at it as a drug problem and not a mental health problem. ... I think that's the depressing thing that will emerge. There will be people with loads of mental health problems as a consequence of this [NPS], and no one will see it as their role'. (SH21, City Centre GP) 
Alongside the need for the integration of mental health and substance use services, the rise in the number of MSM involved in chemsex necessitates the integration of sexual health and substance use services. In November 2015, Public Health England produced guidance for commissioners regarding the contracting and delivery of substance misuse services for MSM involved in chemsex (Public Health England 2015). It was evident that many of the recommendations outlined by PHE were already in place in Manchester including the recent integration of sexual health and substance use teams. The REACH clinic, for example, is a partnership between the Hathersage Sexual and Reproductive Health Service (where the service is currently located) and the integrated drug and alcohol service.

'It's an ideal partnership because to address chemsex you need to go to sexual health clinics for the risk assessments and care, you need the expertise of behavioural interventions that drugs services can provide, and you need an LGBT charity for the cultural competency that goes with LGBT experiences'. (SH11, Chemsex Practitioner)

The need to work in partnership with local LGBT organisations and to ensure substance use practitioners are culturally competent and knowledgeable in relation to this user group was also frequently highlighted.

'Everyone's aware of chemsex now, a little bit, but you need someone that knows what they're talking about in the services for those people that do present... otherwise you'll just lose them very quickly. The same way you'd lose anyone that presented to any service that didn't know what they're talking about'. (SH23, Senior Substance Use Practitioner)

\section{Clearer referral pathways}

The changing profile of intravenous drug users that we highlight in this paper through the combination of the emergence of the MSM chemsex scene coupled with the documented shift away from heroin and crack to SCRAs amongst the homeless population has particular implications for established criminal justice referral pathways into treatment services. Over the past two decades, with the advent of New Labour's Tough Choices and subsequent introduction of the Drugs Intervention Programme (DIP) in 2003, there has been a growing reliance on criminal justice referral routes into treatment services (Duke 2006; Seddon et al. 2012). Indeed, figures from the NDTMS show that criminal justice referrals into treatment for opiate use (28 per cent) were second only to self-referrals (47 per cent) (Knight 2015). This 'criminal justice turn' (Seddon et al. 2009; Seddon et al. 2012) is based on the rhetoric and evidence that suggests a clear link between problematic drug use and acquisitive crime (Bennet \& Holloway 2009; Cabinet Office 1998; Godfrey et al. 2002; Holloway \& Bennett 2004). However, unlike the traditional profile of dependent users of opioids and crack cocaine, SCRAs users are not coming into treatment services via established criminal justice pathways that focus on acquisitive crimes committed by drug users. The test on arrest process fails to detect many SCRAs in circulation. Indeed, as recent studies have highlighted (Ralphs et al. 2017; User Voice 2016), the non-detectability of SCRAs in mandatory drug tests is a key motivator for use in custodial settings (and continued use upon release). Added to this change, MSM who inject are also much less likely to fit the profile of traditional intravenous users who are directed into treatment through the criminal justice system. As we have illustrated, they are resistant to accessing traditional service provision due to the stereotypes associated with this client group. Therefore, we assert that it is important to ensure clear referral pathways exist beyond the traditional criminal justice routes into treatment (Pirona et al. 2017). For example, where appropriate support services did exist, the vast majority of both SCRA users and professionals we interviewed were seemingly unaware of what services and support was available in Manchester. 
'It's hard to know who to refer to at the moment with Spice... There's no one you could directly refer anyone that uses Spice to. Who do you refer to? What can people access? We don't know'. (SH22, Supported Housing Manager)

This lack of clear referral pathways through agencies and poor information and knowledge about what was available led to few referrals or self-referrals into services. It appeared that users and key stakeholders were of the view that new drugs require new services and that existing service support was only for traditional substances such as alcohol, cannabis, cocaine and heroin. The lack of clarity around referral pathways we identified necessitates a review of existing partnership working to ensure better care pathways and the facilitation of inter-agency communication between services. In light of the links we established between the use of SCRA and drugs associated with the chemsex scene and poor mental health, there is now a critical need to establish clearer referral pathways to support services for users who have substance use issues and mental health problems (Section 5.14, Public Health England 2014b). Although we acknowledge that the impact of substance use on user's mental health is not unique to users of NPS it appeared particularly acute within these two NPS sub-populations.

In addition to establishing clearer mental health pathways, the nature of chemsex and STI and BBV risks require robust referral pathways via sexual health services. Medical staff who are in contact with MSM for STIs and for $\mathrm{PrEP}^{\mathrm{v}}$ and PEP need to be trained in the appropriate identification and referral of chemsex users into services. It is imperative that stakeholders agree a patient pathway that includes not only pathways into services but also pathways between services. The establishment of clear NPS treatment pathways also needs to be developed through effective working alliances and collaborative partnerships with emergency services, criminal justice agencies, housing providers, and third sector organisations (e.g. LGBT and Homeless charities). This should also include clear signposting and marketing of what services currently offer when supporting specific NPS users. The recently updated NICE guidance on coexisting severe mental illness and substance misuse (Section 1.4, NICE 2016) provides useful best practice advice on partnership working between specialist services, health, social care and other support services and commissioners.

\section{Developing innovative service user engagement strategies}

In addition to ensuring that clear referral pathways for NPS users exist, we further propose the need to develop appropriate service engagement strategies. Our findings suggest a clear need for more innovation in developing service user engagement strategies that need to include more targeted outreach and in-reach, a review of current marketing strategies, and the location of service provision. Bearing in mind that nearly half of all substance users entering treatment are self-referred (Knight 2015) it is clear that awareness raising is required about what services are available.

As highlighted above, many dependent homeless users of SCRAs do not engage with treatment services because of the stigma associated with drugs services and/or inaccurate knowledge of the services and support currently available. Yet we found that the majority of homeless users did engage with a wide range of generic non-statutory services targeted specifically at the homeless community, including for example, homeless drop-ins, day centres and soup kitchens. This highlights the need for improved inter-agency working between treatment services and those organisations and services that work with the homeless population. In terms of engaging with the chemsex population, Bourne et al. (2014) found that chemsex drugs were consumed in saunas, 'backrooms' or sex clubs. In line with this, we found that bars holding fetish nights and city centre saunas in Manchester were frequented by MSM. With this in mind, these locations would be key sites for outreach work with the chemsex population. As evidenced in the quote below, innovative outreach methods were beginning to emerge during the fieldwork period. 
'We've been doing late night outreach... trying to reach groups of MSM who we don't believe access our services at the moment... An example is we go to [a local fetish night] every four weeks'. (SH20, LGBT Health and Wellbeing Service Lead)

While the above discussion has focused on targeting the physical locations frequented by those involved in chemsex, outreach in virtual spaces was suggested as equally important. The centrality of Apps such as Scruff, Growlr and Grindr to the chemsex scene led many interviewees to discuss the need for a webbased presence, where services can interact and promote what they do.

'I'm not sure if the NHS operates any sexual health Apps or anything, [but] that would be really, really useful... A way that people could find out where their nearest clinics and testing times [are], and all that kind of stuff for different things. Just really discretely and really simply'. (MSM6 late 20s Male Sex Work)

Some of this 'virtual' outreach and support was already operating in Manchester. The LGBT Foundation for instance, have developed some innovative methods of engagement with App users.

'We've done [virtual] outreach for the past couple of years, going on Grindr and Gaydar and stuff, offering information, support and advice. In the last 12 months, we've started doing late night sessions, so on a Friday night we're online between 8 and midnight. And we are going [online] on Saturdays to try and reach a slightly different cohort of guys than we would during the earlier evening outreach... We've got our own profile on Grindr as well so we can send targeted messages, which is a great way of promoting services like the REACH clinic'. (SH18, LGBT Service Engagement Lead)

Related to the point about services being available outside of the 'usual Monday to Friday, 9 to 5 slot', MSM who were not accessing existing drug treatment services and needle exchanges called for a move away from traditional operating hours and locations towards outreach and 'pop-up' services. The demand for pop-up services was raised particularly by MSM in relation to needle exchange provision in the city. Our findings suggest this change in the profile of injecting substance users' needs to be reflected in the provision of needle exchanges and safe injecting information.

\section{Conclusion}

This paper commenced by outlining the debate that has ensued concerning the significance and impact of emerging NPS drug trends for traditional substance use treatment services. Specifically, whether or not bespoke services for NPS users are required or whether existing service provision is adequate. The findings presented in this paper from research conducted in one English city (Manchester) may of course vary dependent on the size of respective homeless and/or MSM communities. Likewise, the nature of the local NPS trends might differ between regions or countries. Nevertheless, we have highlighted a noteworthy shift in the drugs repertoire and methods of ingestion commonly used among sections of the homeless and MSM communities in a city that has often been at the forefront of emerging (problematic and recreational) drug trends (Pearson et al. 1986; Redhead 1993). This shift in the drug using landscape is characterised by a homeless population who would have traditionally been viewed as problematic drug users, associated with the intravenous injection of substances such as heroin and/or crack cocaine, now smoking SCRAs. Concomitantly, we have highlighted how some sections of the LGBT community (namely MSM engaged in chemsex) who would have traditionally been perceived as recreational drug users (using, for example, ecstasy and other stimulants) are now displaying patterns of problematic drug use, including intravenous drug using behaviours more traditionally associated with offending populations 
and groups with low socioeconomic status. Further blurring the dichotomy between recreational and problematic drug use (Askew 2016; Macdonald \& Marsh 2002).

Despite the clear parallels between the physical and mental health harms associated with their NPS use and those traditionally associated with problematic drug use (see Gray et al. forthcoming), the fact that many of these NPS users distanced themselves from the traditional profile of a problematic drug user in need of treatment is an important finding for service providers and commissioners. Regardless of the reality, the stereotypical perceptions and outdated views of users (and some stakeholders) that we uncovered amongst a range of professionals and experienced substance users - namely that drug services are solely places for injecting heroin and crack cocaine users - provides evidence of the need for services to better promote the range of interventions that they offer for NPS and other substances. Therefore, while the discourse on NPS and treatment services has tended to focus on whether or not treatment services need to develop bespoke services for NPS users, alongside increasing staff competency, this paper has highlighted that while existing traditional interventions may be applicable to working with NPS drug users, the focus needs to shift to addressing the problem of non-engagement. The low levels of service user engagement within these groups suggests that treatment services need to develop a more nuanced and targeted approach to engaging NPS using populations into their services. We suggest that this is achievable through the adoption of innovative engagement strategies, alongside the awareness raising of the NPS service offer to both users and stakeholders. In the absence of pharmacological interventions to treat withdrawal, for homeless SCRA users, engagement strategies must include targeted street outreach to increase initial engagement and provide harm reduction advice, coupled with 'inreach' whereby service providers deliver pop-up services in a range of key homeless day centres and supported accommodation providers. For MSM involved in chemsex, the interplay between high-risk substance use and sexual activity, coupled with the stigma and shame associated with chemsex, necessitates psychosexual interventions alongside more traditional psychosocial treatments. This needs to be developed alongside increased accessibility to services. For this particular user group, this dictates the need for more accommodating opening hours, more pop-up services in key locations, along with a portfolio of targeted engagement strategies, such as physical outreach (gay saunas, fetish clubs) and 'virtual' outreach (Apps and online).

The complex and interrelated needs exhibited by these user groups makes it imperative that practitioners and public health commissioners also identify referral pathways that include both pathways into services as well as pathways between services. For the two subpopulations of NPS users focused on in this paper, better integration of substance use services with mental health, sexual health and supported housing and homeless services is essential. In order to respond to local needs it has been proposed that services should be able to detect, access and manage people with serious NPS-related problems to prevent mismanagement and misdiagnosis (Pirona et al. 2017). Consequently, it is imperative that a range of professionals including GPs, mental health, sexual health and housing staff are trained so that they feel equipped and able to identify substance use needs (Bowden-Jones et al. 2014). Alongside this, treatment service staff need to be trained to ensure that they are equipped and feel competent in dealing with the issues that commonly co-exist within these user groups. This would minimise the issue of NPS users being passed back and forth between substance use and mental health services. These recommendations are in line with the good practice prompts outlined in Public Health England's JSNA support pack for 2015-16 (Public Health England 2014b) which summarises the key principles that local areas should reflect upon when developing an integrated alcohol and drugs prevention, treatment and recovery system. We assert that if appropriate referral pathways and engagement strategies are not in place then these groups will continue to under engage, and problems related to these emerging drug use patterns will continue to manifest. 


\section{References}

All-Party Parliamentary Group for Drug Policy Reform. (2013). Towards a Safer Drug Policy: Challenges and Opportunities arising from 'legal highs. Report of an Inquiry into new psychoactive substances. Retrieved from: https://docs.google.com/file/d/0B0c 8hkDJu0DODg3UXpfa2U0SFk/edit

Almeida, J., Johnson, R.M., Corliss, H.L., Molnar, B.E., \& Azrael, D. (2009). Emotional distress among LGBT youth: the influence of perceived discrimination based on sexual orientation. Journal of Youth and Adolescence, 38, 1001-1014.

Antoniou, T. \& Tseng, A.L. (2002). Interactions between recreational drugs and antiretroviral agents. Annals of Pharmacotherapy, 36, 1598-1613.

Askew, R. (2016). Functional fun: legitimising adult recreational drug use. International Journal of Drug Policy, 36, 112-119.

Barratt, M.J., Cakic, V. \& Lenton, S. (2013). Patterns of synthetic cannabinoid use in Australia. Drug and Alcohol Review, 32, 141-146.

BBC1 (2016) Professor Green: Hidden and Homeless $24^{\text {th }}$ February 2016. [Video] Available from: http://www.bbc.co.uk/programmes/b070jqms

Bebarta, V.S., Ramirez, S. \& Varney, S.M. (2012). Spice: A new 'legal' herbal mixture abused by young active duty. Substance Abuse, 33(2), 191-194.

Bennett, T. \& Holloway, K. (2009). The Causal Connection Between Drug Misuse and Crime. The British Journal of Criminology, 49(4), 513-531.

Blackman, S. \& Bradley, R. (2017). From niche to stigma - Headshops to prison; exploring the rise and fall of synthetic cannabinoid use amongst young adults. The International Journal of Drug Policy, 40, 70-77.

Bourne, A., Reid, D., Hickson, F., Torres, R.S. \& Weatherburn, P. (2014). The Chemsex Study: Drug use in Sexual Settings Among Gay and Bisexual Men in Lambeth, Southwark and Lewisham. Sigma Research, London School of Hygiene \& Tropical Medicine. Retrieved from: http://researchonline.lshtm.ac.uk/id/eprint/2197245

Bourne, A., Reid, D., Hickson, F., Torres-Rueda, S., Steinberg, P. \& Weatherburn, P. (2015).

"Chemsex" and harm reduction need among gay men in South London. The International Journal of Drug Policy, 26(12), 1171-1176.

Bowden-Jones, O., Fitch, C., Hilton, C., Ofori-Attah, G. \& Lewis, J. (2014). One new drug a week: Why novel psychoactive substances and club drugs need different response from UK treatment providers. Faculty of Addictions Psychiatry, Royal College of Psychiatrists. Retrieved from: https://www.rcpsych.ac.uk/pdf/FR\%20AP\%2002_Sept2014.pdf

Cabinet Office. (1998). Tackling Drugs to Build a Better Britain. London: HMSO.

Castellanos, D., Singh, S., Thornton, G., Avila, M., \& Moreno, A. (2011). Synthetic cannabinoid use: A case series of adolescents. Adolescent Health, 49(4), 347-349.

Chatwin, C., Sumnall, H., Measham., F \& O’Brien, K. (2017) New drugs, new directions? Research priorities for new psychoactive substances and human enhancement drugs. The International Journal of Drug Policy, 40, 1-5.

Cohen, S. \& Taylor, L. (1976). Escape attempts: The theory and practice of resistance to everyday life. London: Allen Lane

Connor, T.J. (2004) Methylenedioxymethamphetamine (MDMA, 'ecstasy'): a stressor on the immune system. Immunology, 111(4), 357-367.

Department of Health (2013) A Framework for Sexual Health Improvement in England. Department of 
Health. Retrieved from: https://www.gov.uk/government/publications/a-framework-for-sexualhealth-improvement-in-england

Dolengevich-Segal, H., Rodríguez-Salgado, B., Gómez-Arnau, J. \& Sánchez-Mateos, D. (2016). Severe Psychosis, Drug Dependence, and Hepatitis C Related to Slamming Mephedrone. Case Reports in Psychiatry 2016. doi: http://dx.doi.org/10.1155/2016/8379562

Drake, R.E., Bartels, S.J., Teague, G.B., Noordsy, D.L. \& Clark, R.E. (1993). Treatment of substance use disorders in severely mentally ill patients. Journal of Nervous and Mental Disease 181(10), 606-611.

Drake, R.E., Essock, S.M., Shaner, A., Carey, K.B., Minkoff, K., Kola, L., Lynde, D., Osher, F.C., Clarke, R.E. \& Rickards, L. (2002). Implementing Dual Diagnosis Services for Clients With Severe Mental Illness. Psychiatric Services, 52(4), 469-476.

Duke, K. (2006). Out of crime and into treatment? The criminalization of contemporary drug policy since Tackling Drugs Together. Drugs: Education, Prevention and Policy, 13(5), 409-415.

EMCDDA. (2016). Perspectives on drugs: Legal approaches to controlling new psychoactive substances. Retrieved from: http://www.emcdda.europa.eu/topics/pods/controlling-newpsychoactive-substances

Every-Palmer, S. (2011). Synthetic cannabinoid JWH-018 and psychosis: An explorative study. Drug and Alcohol Dependence, 117(2-3), 152-157.

Fountain, J. \& Howes, S. (2001). Rough Sleeping, Substance Use and Service Provision in London. National Addiction Centre, London.

Godfrey, C., Eaton, G., McDougall, C. \& Culyer, A. (2002). The Economic and Social Costs of Class A Drug Use in England and Wales, 2000. Home Office Research Study 249. London: Home Office.

Gray, P., Ralphs, R. \& Norton, A. (forthcoming). "Green heroin"? The motivations for the use of, and the harms associated with dependent use of synthetic cannabinoid receptor agonists amongst the homeless community in Manchester. Addiction Research \& Theory.

Halkitis, P.N., Kutnick, A.H., \& Slater, S. (2005). The social realities of adherence to protease inhibitor regimens: substance use, health care and psychological states. Journal of Health Psychology, 10(4), 545-558.

Harrington, R.D., Woodward, J.A., Hooton, T.M, \& Horn, J.R. (1999). Life-threatening interactions between HIV-1 protease inhibitors and the illicit drugs MDMA and gamma-hydroxybutyrate. Archives of Internal Medicine, 159, 2221-2224.

Harris, C.R. \& Brown, A. (2013). Synthetic cannabinoid intoxication: A case series and review. Journal of Emergency Medicine, 44, 360-366.

Haubrich, R.H., Little, S.J. \& Currier, J.S. (1999). The value of patient-reported adherence to antiretroviral therapy in predicting virologic and immunologic response. AIDS, 13, 1099-1107.

Health Scrutiny Committee. (2016). Manchester City Council Report for Resolution. Retrieved from: www.manchester.gov.uk/download/meetings/id/20781/8 sexual health

Henry, J.A. \& Hill, I.R. (1998). Fatal interaction between ritonavir and MDMA. Lancet, 352, 17511752.

Hickson, F., Melendez-Torres, G.J. \& Reid, D. (2017). HIV, sexual risk and ethnicity among gay and bisexual men in England: survey evidence for persisting health inequalities. Sexually

Transmitted Infections. doi: http://dx.doi.org/10.1136/sextrans-2016-052800

HMIP. (2014). HM Chief Inspector of Prisons for England and Wales: Annual report 2013-14.

Retrieved from:

https://www.justiceinspectorates.gov.uk/hmiprisons/wpcontent/uploads/sites/4/2014/10/HMIP-

AR 2013-14.pdf

HMIP. (2015). Changing patterns of substance misuse in adult prisons and service responses: A thematic 
review by HM Inspectorate of Prisons. Retrieved from:

https://www.justiceinspectorates.gov.uk/hmiprisons/wp-

content/uploads/sites/4/2015/12/Substance-misuse-web-2015.pdf

HMIP. (2016). HM Chief Inspector of Prisons for England and Wales: Annual report 2015-16.

Retrieved from:

https://www.gov.uk/government/uploads/system/uploads/attachment_data/file/538854/hmipannual-report.pdf

Holloway, K. \& Bennett, T. (2004). The Results of the First Two-Years of the NEW-ADAM

Programme. London: The Home Office.

Home Office. (2014). New psychoactive substances review: Report of the expert panel. Retrieved

from:

https://www.gov.uk/government/uploads/system/uploads/attachment data/file/368583/NPSexper $\underline{\text { tReviewPanelReport.pdf) }}$

Homeless Link. (2014). Health Audit. Retrieved from:

http://www.homeless.org.uk/our-work/resources/homeless-health-needs-audit

Hurst, D., Loeffler, G., \& McLay, R. (2011). Synthetic cannabinoid agonist induced psychosis a case series. Retrieved from: http://www.ncis.navy.mil/PI/CRP/Documents/Spice\%20APA\%20poster.pdf

Johnson, T.P., Freels, S.A., Parsons, J.A. \& Vangeest, J.B. (1997). Substance abuse and homelessness: social selection or social adaptation? Addiction, 92(4), 437-445.

Keogh, P., Reid, D., Bourne, A., Weatherburn, P., Hickson, F., Jessup, K. \& Hammond, G. (2009).

Wasted opportunities: problematic alcohol and drug use among gay men and bisexual men.

Technical Report. London: Sigma Research.

King, M., Semlyen, J., \& Tai, S. (2008). A systematic review of mental disorders, suicide and deliberate self-harm in lesbian, gay and bisexual people. BMC Psychiatry, 8(70), 1-17.

Kirby, T. \& Thornber-Dunwell, M. (2013). High-risk drug practices tighten grip on London gay scene. Lancet, 381, 101-102.

Klee, H. \& Reid, P. (1998). Drug use among the young homeless: coping through self-medication.

Health: An Interdisciplinary Journal for the Social Study of Health, Illness and Medicine, 2(2), 115-134.

Knight, J. (2015). Adult substance misuse statistics from the National Drug Treatment Monitoring System (NDTMS) 1 April 2014 to 31 March 2015. London: Public Health England.

Local Government Association. (2015). A councillors' guide to tackling new psychoactive substances. Retrieved from: http://www.local.gov.uk/documents/10180/6869714/A+councillors\%27\%20guide+to+tackling + w+psychoactive+substances.pdf/c2055374-dff2-4717-8aed-94b1d1e08d7a

MacDonald, R. \& Marsh, J. (2002). Crossing the Rubicon: youth transitions, poverty, drugs and social exclusion. The International Journal for Drug Policy, 13(1), 27-38.

McCleod, K. (2012). Successful interventions with new psychoactive substances. Retrieved from: https://www.globaldrugsurvey.com/katy-mcleod/

McFall, S.L. (2012). Understanding Society: Findings 2012. Colchester: Institute for Social and

Economic Research, University of Essex. Retrieved from:

https://www.understandingsociety.ac.uk/research

Ministry of Justice. (2016). Offender Management Statistics Bulletin, England and Wales Quarterly October to December 2015 - Annual January to December 2015. Ministry of Justice. Retrieved from:

https://www.gov.uk/government/uploads/system/uploads/attachment data/file/519437/offendermanagement-statistics-quarterly-bulletin-oct-dec-2015.pdf 
Minkoff, K. (1991). Program components of a comprehensive integrated care system for serious mentally ill patients with substance disorders. Dual Diagnosis of Serious Mental Illness and Substance Disorder. New Directions for Mental Health Services, 50, 13-27.

Minkoff, K. (2001). Best Practices: Developing Standards of Care for Individuals With Co-occurring Psychiatric and Substance Use Disorders. Psychiatry online, 52(5), 597-599.

NEPTUNE. (2015). Guidance on the Clinical Management of Acute and Chronic Harms of Club Drugs and Novel Psychoactive Substances. Retrieved from:

http://www.emcdda.europa.eu/attachements.cfm/att_236560_EN_UK10_NEPTUNE\%20NPS\%2 0guidance\%20(2015).pdf

NICE. (2016). Coexisting severe mental illness and substance misuse: community health and social care services. NICE guideline. Retrieved from: https://www.nice.org.uk/guidance/ng58/chapter/recommendations

Pacifici, R., Zuccaro, P. \& Farre, M. (2001a). Effects of repeated doses of MDMA ('ecstasy') on cellmediated immune response in humans. Life Sciences, 69(24), 2931-2941.

Pacifici, R., Zuccaro, P. \& Hernandez, L.C. (2001b). Acute effects of 3,4methylenedioxymethamphetamine alone and in combination with ethanol on the immune system in humans. Journal of Pharmacology and Experimental Therapeutics, 296(1), 207-215.

Parker, H., Newcombe, R. \& Bakx, K. (1987). The New Heroin Users: prevalence and characteristics in Wirral, Merseyside. British Journal of Addiction, 82(2), 147-157.

Parker, H., Aldridge, J. \& Measham, F. (1998). Illegal Leisure: The Normalization of Adolescent Recreational Drug Use. London: Routledge.

Parker, H., Measham, F. \& Aldridge, J. (1995). Drugs Futures: Changing Patterns of Drug Use Amongst English Youth. London: Institute for the Study of Drug Dependence.

Pearson, G. (1987). The New Heroin Users. Oxford: Wiley-Blackwell.

Pearson, G., Gilman, M. \& McIver, S. (1986). Young People and Heroin: An Examination of Heroin Use in the North of England. London: Health Education Council.

Perraudin, F. (2017). Manchester police attend 58 spice-linked incidents in one weekend. The Guardian. Retrieved April 15, 2017, from: https:/www.theguardian.com/uknews/2017/apr/10/manchester-police-calls-linked-zombie-drug-spice

Pilkington, H. (2006). 'For us it is normal': Exploring the 'Recreational' Use of heroin in Russian youth cultural practice. Journal of Communist Studies and Transition Politics, 22(1), 24-53.

Pirona, A., Bo, A., Hedrich, D., Ferri, M., van Gelder, N., Giraudon, I., Montanari, L., Simon, R., \& Mounteney, J. (2017). New psychoactive substances: Current health related practices and challenges in responding to use and harms in Europe. The International Journal of Drug Policy, 40, 84-92.

Public Health England. (2014a). Promoting the Health and Wellbeing of Gay, Bisexual and Other Men Who Have Sex With Men. Initial Findings. Retrieved from: https://www.gov.uk/government/uploads/system/uploads/attachment data/file/339041/MSM_Init ial Findings GW2014194.pdf

Public Health England. (2014b). Drug prevention, treatment and recovery for adults: JSNA support pack. Good practice prompts for planning comprehensive interventions in 2015-16. Retrieved from: http://www.nta.nhs.uk/healthcare-JSNA.aspx

Public Health England. (2015). Substance misuse services for men who have sex with men involved in chemsex. Briefing for Commissioners. Public Health England, November 2015. Retrieved from: http://londonfriend.org.uk/wp-content/uploads/2015/11/phe-substance-misuse-services-for-msminvolved-in-chemsex.pdf

Ralphs, R., Williams, L., Askew, R. \& Norton, A. (2017). Adding Spice to the Porridge: The development of a synthetic cannabinoid market in an English prison. International Journal of 
Drug Policy, 40, 57-69.

Redhead, S. (1993). Rave off: Politics and deviance in contemporary youth culture (Vol. 1). Avebury: Ashgate Publishing Limited

Romanelli, F., Smith, K.M., \& Pomeroy, C. (2003). Use of club drugs by HIV-seropositive and HIVseronegative gay and bisexual men. Topics in HIV Medicine, 11(1), 25-32.

Seddon, T., Ralphs, R. \& Williams, L. (2009). Risk, security and the 'criminalization' of British drug policy. British Journal of Criminology, 48(6), 818-834.

Seddon, T., Williams, L. \& Ralphs, R. (2012). Tough Choices: Risk, Security and the Criminalization of Drug Policy. Oxford: Oxford University Press

SIGMA. (2016). State of Play: findings from the England Gay Men's Sex Survey 2014. Sigma

Research, London School of Hygiene \& Tropical Medicine. Retrieved from: http://sigmaresearch.org.uk/files/GMSS-2014-State-of-Play.pdf

Stevens, A., Fortson, R., Measham, F. \& Sumnall, H. (2015). Legally flawed, scientifically problematic, potentially harmful: The UK Psychoactive Substance Bill. International Journal of Drug Policy, 26(12), 1167-1170.

Sumnall, H., Hamilton, I. \& Monaghan, M. (2017). Novel Psychoactive Substances: important information for health professional. Retrieved from: https://www.nationalelfservice.net/mentalhealth/substance-misuse/novel-psychoactive-substances-important-information-for-healthprofessionals/

The Vice. (2014). 'Spice Boys'. Available from: https://video.vice.com/en uk/video/the-hard-lives-of-britains-synthetic-marijuanaaddicts $/ 55 \mathrm{ccad} 2 \mathrm{~d} 2 \mathrm{~b} 68305332 \mathrm{db} 7128$

Thomas, S., Bliss, S. \& Malik, M. (2012). Suicidal ideation and self-harm following K2 use. Oklahoma State Medical Association, 105(11), 430-433.

Thornton, S. (1995). Club Cultures: Music, Media, and Subcultural Capital. Cambridge: Polity Press

Tracy, D.K., Wood, D.M. \& Baumeister, D. (2017). Novel psychoactive substances: identifying and managing acute and chronic harmful use. BMJ, 2017, 356.

User Voice. (2016). Spice: The bird killer — what prisoners think about the use of spice and other legal highs in prison. Retrieved from: http://www.uservoice.org/wp-content/uploads/2016/05/UserVoice-Spice-The-Bird-Killer-Report-Low-Res.pdf

Van Der Veer, N. \& Friday, J. (2011). Persistent psychosis following the use of Spice. Schizophrenia Research, 130(1-3), 285-286.

Williams, J. (2017a). The pale, wasted figures caught in a Spice nightmare that's turning Piccadilly Gardens into hell on earth. Manchester Evening News. Retrieved April 12, 2017, from: http://www.manchestereveningnews.co.uk/news/greater-manchester-news/spice-nightmaremanchester-city-centre-12870520

Williams, J. (2017b). Tackling the Spice epidemic is the top election issue for voters in Manchester. Manchester Evening News. Retrieved March 20, 2017, from: http://www.manchestereveningnews.co.uk/news/greater-manchester-news/tackling-spiceepidemic-top-election-13040629

Williams, J. \& Macpherson, J. (2017). Disturbing video shows how new strain of Spice turns Manchester's homeless into walking dead. Manchester Evening News. Retrieved March 7, 2017 , from: http://www.manchestereveningnews.co.uk/news/greater-manchester-news/disturbingvideo-shows-how-new-12695865

Williams, L. \& Parker, H. (2001). Alcohol, Cannabis, Ecstacy and Cocaine: Drugs of reasoned choice amongst young adult recreational drug users in England. The International Journal for Drug Policy, 12(5-6), 397-413.

Zimmermann, U.S., Winkelmann, P.R., Pilhatsch, M., Nees, J.A., Spanagel, R. \& Schulz, K. (2009). 
Withdrawal phenomena and dependence syndrome after the consumption of 'Spice Gold'. Deutsches Ärzteblatt International, 106(27), 464-467.

\footnotetext{
' NPS are either newly manufactured to mimic the effects of traditional drugs (e.g. synthetic cathinone's and SCRA receptor agonists) or pre-existing drugs used in a novel way (e.g. nitrous oxide and ketamine).

ii Other recreational drugs can also play a role in chemsex, although they are deemed to be less prevalent and secondary to the use of these three main substances.

iii 'Slamming' is the terms used by MSM to describe the intravenous injection of mephedrone and crystal methamphetamine.

iv The REACH clinic is Manchester's dedicated service for chemsex, located in the sexual health clinic.

v PrEP stands for 'pre exposure prophylaxis'. PEP stands for 'post exposure prophylaxis'. PrEP is an HIV medication taken before an exposure to prevent any possible transmission. PEP are HIV drugs taken after you have had an exposure. This reduces the chance of an infection.
} 